Revista de la red interuniversitaria de estudios sobre las literaturas rioplatenses contemporáneas en Francia

$11 \mid 2014$

De niños e infancias

\title{
La infancia como falta
}

Daniel Link

\section{OpenEdition}

Journals

\section{Edición electrónica}

URL: http://journals.openedition.org/lirico/1798

DOI: $10.4000 /$ lirico. 1798

ISSN: 2262-8339

Editor

Réseau interuniversitaire d'étude des littératures contemporaines du Río de la Plata

Referencia electrónica

Daniel Link, «La infancia como falta », Cuadernos LIRICO [En línea], 11 | 2014, Puesto en línea el 01

diciembre 2014, consultado el 01 mayo 2019. URL : http://journals.openedition.org/lirico/1798 ; DOI : 10.4000/lirico.1798

Este documento fue generado automáticamente el 1 mayo 2019.

\section{(c) $(1) \Theta \Theta$}

Cuadernos LIRICO está distribuido bajo una Licencia Creative Commons Atribución-NoComercialSinDerivar 4.0 Internacional. 


\title{
La infancia como falta
}

\author{
Daniel Link
}

1 Quiero agradecer la amable y generosa invitación de Julio Premat para integrarme a esta interrogación colectiva de la infancia emprendida por los prestigiosos Cuadernos LIRICO, una interrogación que me obliga a desandar un camino y a retomar algunas hipótesis dispersas en algunos libros míos (Link, 2009a) y a considerarlas, ahora, respecto de un territorio, el Río de la Plata (y sus culturas), que yo, por razones de tiempo, consideraré sólo desde una orilla, su banda occidental.

2 Pero como el acento de mi exposición estará puesto en las ficciones de infancia, o en la teoría de la infancia, tal vez podamos luego evaluar su alcance respecto del corpus cisplatino. Dije ficciones y teoría y debería haber dicho ficciones teóricas porque la infancia es al mismo tiempo un relato (un cuento), una postulación sobre la dimensión históricotrascendental del hombre (Agamben, 1978: 74), un mito, aquello que transforma los acontecimientos en estructuras, y un juego, aquello que transforma las estructuras en acontecimientos (Lévi-Strauss, 1962a : 44-47). O, dicho de otro modo : la infancia se instala (sucede) en el hiato entre el relato y el teorema, y establece una distancia diferencial entre lo propio del rito y lo propio del juego (y su potencia profanadora).

3 En un libro clásico, René Schérer y Guy Hocquenguem han subrayado que todo pensamiento sobre la infancia que pretenda conservar los términos "libertad" e "infancia" (¿es el niño libre o no ?, ¿es el niño un hombre o no ?) es una contradictio in adjectio y escapa a la razón. $Y$ además :

En el pensamiento sobre la infancia hay algo que desborda el concepto (la

"animalidad" de sus inclinaciones, lo "virtual" de su libertad). Proponemos, para connotar esa mezcla en el niño de humanidad e inhumanidad, de responsabilidad e irresponsabilidad, la expresión idea inexponible de la imaginación, y planteamos que dicha idea es de la misma naturaleza que la idea estética (Schérer y Hocquenguem, $1976: 68-69)$.

4 La idea infancia, entonces, es de la misma naturaleza que la idea estética : y "misma naturaleza" quiere decir aquí aire de familia, forma de parentesco que, para despertar apenas a la bestia analítica del sopor en el que se encuentra, nos convendrá, por el momento, asignar al mismo tótem (Ototeman, precisa Lévi-Strauss, significa 
aproximadamente "él es de mi parentela" 1 ) : ideas primas, podríamos decir. Y todos los argumentos respecto de la infancia serán, en algún sentido, argumentos primos de los argumentos respecto del arte. Me detengo en algunos.

Giorgio Agamben sugiere que la teoría de la infancia, como original dimensión históricotrascendental del hombre, adquiere todo su sentido si se la pone en relación con la distinción formulada por Emile Benveniste entre los modos de significación semiótico y semántico. Como se recordará, para Benveniste esos dos órdenes de significación permanecen separados y no se comunican. La teoría de la infancia se postula como respuesta al problema del hiato existente entre esos dos órdenes : para hablar, el hombre necesita despojarse de la infancia, es decir: rompe el mundo cerrado del signo y transforma la pura lengua en discurso humano: "Lo semiótico no es más que la pura lengua prebabélica de la naturaleza, de la que el hombre participa al hablar, pero de donde siempre está saliendo en la Babel de la infancia" (79). Por eso la infancia del hombre puede identificarse con el origen de la experiencia y de la historia, es decir del acontecimiento (aquello en que las estructuras se transformaban por la vía del juego y su potencia profanatoria).

Para Agamben, "la infancia es precisamente la máquina (...) que transforma la pura lengua prebabélica en discurso humano, la naturaleza en historia" (88). El misticismo, por eso, entendido como un padecer, un páthêma excluido del lenguaje, un no-poder-decir, es una experiencia bastante cercana a la experiencia de la infancia del hombre.

7 La gran poeta rioplatense de la infancia es sin duda Alejandra Pizarnik (quien no casualmente es, también, una de las grandes místicas). Cierta vez, examinando los libros de su biblioteca (Link, 2009) descubrí entre sus muchos tesoros un libro en alemán, un "librito de rimas infantiles" que "fue muy importante para ella" (según me dijo su albacea literaria, Ana Becciu ${ }^{2}$ ). Se trata de Blumen-Märchen, con textos e ilustraciones de Ernst Kreidolf (Kreidolf, 1952). Como su título lo indica, todos los poemas y dibujos son sobre flores y jardines. A veces se trata de una fiesta a la luz de los insectos, a veces de un debate florido. No hace falta recordar que lo floral es otro de los motivos más transitados por los poemas de Pizarnik, "en el cerebro flores pequeñas/ danzando como palabras en la boca de un mudo" (Pizarnik, 2001 :107), junto con las muñecas y las niñas muertas (autómatas o fantasmas, restos de Persona que, junto con el humor, los objetos de la vida cotidiana e, incluso, el cuerpo, fueron decisivamente sacrificados en el altar de un ars poetica sin concesiones, un juego a muerte).

8 El jardín de Blumen-Märchen, como a veces el jardín pizarnikiano, está habitado por la Gracia y las figuritas encantadas de las flores parlantes (como los mundos de Alicia, que tanto le gustaban). Si Pizarnik atesoró este libro infantil es porque podía leer en él "la atmósfera interior de su infancia" (Pizarnik, 2003b : 210), esa infancia que es, al mismo tiempo, la propia y la infancia de la humanidad, perdida y olvidada en la catástrofe de una Historia congelada para siempre.

9 Henri Michaux, escribe Pizarnik, "ilustra esta pérdida definitiva con un magnífico ejemplo". Y cita (es decir, lee, subraya, recorta, guarda y rememora) :

A los ocho años, Luis XIII hace un dibujo parecido al que hace el hijo de un caníbal de Nueva Caledonia. A los ocho años, tiene la edad de la humanidad, tiene por lo menos doscientos cincuenta mil años. Algunos años más tarde los ha perdido, no tiene más que treinta y uno, se ha vuelto un individuo, no es más que un rey de Francia, atolladero del que no saldrá nunca. (Pizarnik, 2003b : 211) 
10 Roger Caillois, un texto del "venerado Michaux"3, "Idées de traverse". Muy marcado, Pizarnik subraya en él "el poder actuar sobre la vida prenatal del hombre" ("Il faudrait pouvoir agir sur la vie prénatale de l'homme ${ }^{4 "}$ ).

11 ¿No es la busca desesperanzada de esa "inocencia perdida", de ese jardín edénico y prebabélico, de ese vida prenatal invocada una y otra vez para que retorne junto con el tiempo lo que la poesía de Pizarnik pretende (como el libro de Proust ${ }^{5}$ ) recuperar para nosotros? No se trata entonces de la invención de un dibujo o un nombre o una musiquita dislocada, sino de la revelación de que el dibujo, el nombre y la musiquita dislocada estaban ya allí, son viejas como el mundo y el poema no hace sino co-existir con esa voz prehistórica y esa "otra velocidad de cicatrización" (Michaux). El poema quiere una música para pedir auxilio en el horror, en el no saber, una música para que diga su desposesión, una música no parecida a ninguna otra sino solamente parecida a él, música para reconocerse, para decir su nombre, una música que señale su lugar, que exprese su carencia de lugar (Pizarnik, 2003b : 209)

Ese lugar o carencia de lugar es el jardín musical de las flores danzantes, un rumor que nos llega de un más allá de lo moderno no porque su combustión haya cesado sino porque los desgarramientos de la Historia todavía no habían sucedido. Si Alejandra Pizarnik añoraba el lenguaje de las flores, la canción de la tierra y la música previa al nacimiento de los hombres (cosa que, en verdad, jamás sabremos), algunas de sus lecturas le señalaron un camino posible diferente del de la teología negativa por el que parece inclinarse la poeta-niña muchas veces. Durante su estancia en París, la poeta cultivó la amistad de André Pieyre de Mandiargues (1909-1991), poeta y novelista. Leyó con placer sus libros. Uno de ellos es el Ruisseau des solitudes suivi de Jacinthes; et de Chapeaugaga (de Mandiargues, 1968). El poema glosolálico, semiótico, Chapeaugaga dice :

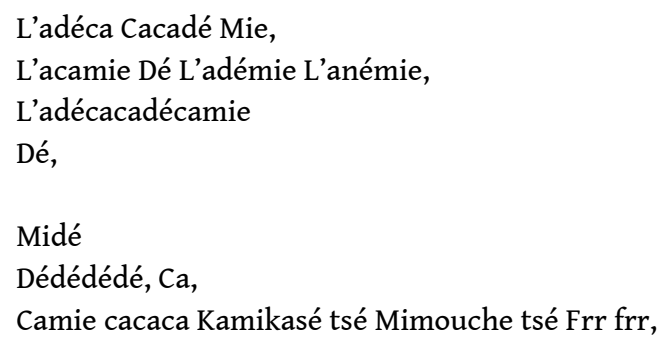

13 Alejandra Pizarnik jamás fue tan atrás, hasta el balbuceo y los fonemas lácteos que se ubican entre lo semiótico y lo semántico, en su intento por recuperar la inocencia perdida. Y sin embargo, en la portadilla del poema de su amigo, escribe : "pas mal".

Como Sigmund Freud mucho tiempo antes que ella, Pizarnik suscribe a la teoría de la recapitulación, según la cual el individuo repite los principales estadios de la evolución de la especie (la ontogenesis resume la filogenesis) y por eso escucha en el poema (de Michaux o de Madiargues), al mismo tiempo, la voz de la infancia de la humanidad y la del individuo.

Heredero de esa teoría de la infancia, Arturo Carrera ha propuesto, por su parte, que si "el niño es la insistencia de la materia vocabular de esa risa", si "hay un niño insistente que no existe que persiste percutiendo y simulando en los ojillos de la noche", si "no hay drama en la infancia : sólo la variación indiferente de una música de insectos y vivísimas alas" (Carrera y Prior, 2007), la infancia no es sólo lo previo al lenguaje, es también la prehistoria de la humanidad, cuando no había teatrillos del yo y el arte se limitaba al rumor 
de los insectos, las bandadas de pájaros, la canción de la tierra. "Se trata de ese que llevamos dentro desde el nacimiento como una especie de ludión que no nos suelta ni después de muertos" (Carrera, $1984: 86$ ).

No es que Carrera repita a Pizarnik. Y si lo hiciera, lo estaría haciendo según la lógica del eterno retorno: lo que vuelve en Carrera está ya marcado por aquello que Pizarnik no tenía en su biblioteca: Deleuze (Carrera, 1995), Schérer, Hocquenguem, Alfredo Prior, Lamborghini.

La infancia, para Carrera, es lo indeterminado en lo determinado, la oscilación entre lo animal y lo humano, una oscilación, digamos, entre lo semiótico y lo semántico, entre el rito y el juego. La infancia, incluso, como pánico : eso que, siempre, ya ha sido, sin llegar a ser la muerte. La literatura, para Arturo Carrera, es el rastro de una ausencia (lo infans como moriturum), que sin embargo nos manda. Uno no canta ni pinta ni traza ni llena las formas con sustancias. Sencillamente oye el ritornello, y baila la canción dichosa de lo previo (Link, 2007).

¿Qué significa asignar a dos ideas la misma naturaleza, adscribirlas al mismo tótem? Como sabemos, en Tótem y tabú. Algunos aspectos comunes entre la vida mental del hombre salvaje y los neuróticos (1913) Sigmund Freud (además de equivocarse antropológicamente en casi todo lo que allí plantea) postuló una reflexión sobre la ley moral (la soberanía) y la culpa. En lugar del origen (que para Freud es mítico : no hubo "horda originaria" nunca), pone un acto real, el asesinato del padre y la posterior reconciliación con su imagen, por la vía del tótem. En lugar del horror al incesto, un acto simbólico, la interiorización de la prohibición, por la vía del tabú.

El término tótem había sido introducido en 1791, tomado de la lengua algonquina que se hablaba en la zona de los Grandes Lagos norteamericanos. Dio origen a la teoría del totemismo, que apasionó a la primera generación de antropólogos, así como la histeria fascinaba, al mismo tiempo, a los médicos. "La moda de la histeria y la del totemismo fueron contemporáneas", escribió Claude Lévi-Strauss. "Se originaron en el mismo ambiente de la civilización". Ese ambiente de civilización, que encontró en la histeria y el tótem dos maneras de hablar del corte y de la división sexual, de las mujeres y de los hombres, arrastró a Sigmund Freud a la ensoñación novelesca, a la invención de una fábula que pretendía resolver la contradicción entre cultura y naturaleza o entre civilización y salvajismo mediante una ficción teórica de profundas consecuencias cuyo análisis escapa a las posibilidades de esta comunicación pero que no podía dejar de mencionar. El animal totémico, como nombre del clan, piensa Freud, resume el hiato entre la especie y el individuo mediante un mismo operador ${ }^{6}$. Algunos años después, LéviStrauss precisará que el tótem no es representación del animal sino máscara, con lo cual se establece una discontinuidad entre lo animal y lo humano. $Y$ en otra vuelta de pensamiento, que vuelve a traernos a las playas de la literatura y el arte, inspirado en esas investigaciones etnográficas, Oscar Masotta, contemporáneo de Alejandra Pizarnik y de Arturo Carrera, maestro odiado de Osvaldo Lamborghini, pensó el arte pop entendiéndolo como "arte de máscaras” y “juego audaz" (Masotta, 1967).

Pero el tótem freudiano no viene sólo sino en pareja. Proveniente de la Polinesia e introducida por el capitán Cook en 1777, la palabra taboo se había difundido con dos acepciones : la primera, específica de sus culturas de origen, la segunda, designando la prohibición en general. En cuanto a la palabra "salvaje" (Wilden), remite a uno de los fundadores de la antropología evolucionista, Lewis Morgan, quien había dividido la 
historia de la humanidad en tres estadios : salvajismo (caza), barbarie (alfarería y útiles de hierro), y civilización (escritura).

21 Me detengo sobre todo en la cuarta parte de Tótem y Tabú, "El retorno infantil al totemismo", que es la más útil (o el más inútil, según se prefiera) para nuestras indagaciones. Como sabemos, Freud pretendía aportar una solución filosófica a la antropología evolucionista (cuyos principios aceptó), que veía en la instauración del tótem la prefiguración del monoteísmo, y en la del tabú, el pasaje de la horda salvaje a la organización del clan. Freud consideró la idea de salvaje como equivalente de la idea de niño y, aunque los conservó, liberó a los estadios evolutivos de toda valoración relativa : el totemismo era para él jerárquicamente idéntico al monoteísmo. Al hacer coincidir la infancia de la humanidad (en la idea del salvaje) y la infancia del individuo (en la idea de niño) pretendía sostener la neurosis infantil como fundamento de la condición humana ${ }^{7}$.

El argumento : En un tiempo primitivo, los hombres vivían en pequeñas hordas, regidas por el poder despótico de un macho que se apropiaba de las hembras. Un día, los hijos de tribu se rebelaron contra el padre, lo mataron y se comieron su cadáver. Arrepentidos, renegaron del crimen y crearon un nuevo orden social, instaurando la exogamia (renuncia a la posesión de las mujeres del clan identificado con un tótem) y el totemismo, basado en prohibir el asesinato del sustituto del padre (el tótem ${ }^{8}$ ). Edipo y totemismo son, para Freud, universales porque en las prohibiciones que implican (asesinato del padre, incesto) se fundan todas las sociedades humanas. Cito :

Si el animal totémico es el padre, resultará, en efecto, que los dos mandamientos capitales del totemismo, esto es, las dos prescripciones tabú que constituyen su nódulo, o sea la prohibición de matar al tótem y la de realizar el coito con una mujer perteneciente al mismo tótem, coincidirán en contenido con los dos crímenes de Edipo, que mató a su padre y casó con su madre, y con los dos deseos primitivos del niño, cuyo renacimiento o insuficiente represión forman quizá el nódulo de todas las neurosis. Si esta semejanza no es simplemente un producto del azar, habrá de permitirnos proyectar cierta luz sobre los orígenes del totemismo en remotísimas épocas, esto es, nos permitirá hacer verosímil la hipótesis de que el sistema totémico constituye un resultado del complejo de Edipo.

Dejemos por un momento a Freud y a la horda primitiva, pero sin abandonar la infancia, la infancia como falta (lo que está antes del lenguaje humano, el rastro de una ausencia) que, sin embargo (o precisamente por eso), funciona como la máquina que produce el acontecimiento, y por lo tanto, la historia.

Trabajo con ficciones teóricas de infancia, no importa que se trate de poemas o relatos. No trabajo con "evocaciones de infancia" porque Sylvia Molloy ya nos enseñó a desconfiar de las trampas de la autobiografía (Molloy, 1991).

Sin embargo, no puedo dejar de citar ciertos trabajos críticos que, en algún sentido, fundamentan mi resistencia a la proposición de un corpus (un cuerpo) de infancia.

En 1982, Raúl Castagnino propuso, en su artículo "Evocaciones de infancia y adolescencia en la literatura argentina", un somero catálogo de libros aparecidos entre 1932 y 1981 organizado alrededor de las "evocaciones de infancia". Esos títulos son: Cuadernos de infancia de Norah Lange, El río distante de Vicente Barbieri, Niñez en Catamarca de Gustavo Levene, Cuando el ayer era mañana de Eduardo González Lanuza, El tiempo más hermoso de Jorge Vocos Lescano, La oscuridad es otro sol de Olga Orozco, País de infancia de Mario Binetti, Memorias de un provinciano de Carlos Mastronardi, Confín de viento y sal de Josefina Marazzi de Rouillón, Adolecer de Nydia Daract de Reina, Retablo tucumano (1981) de Teresa Piossek Prebisch (Castagnino,1982). 
27 La lista oscila entre el federalismo, el humor involuntario y el capricho, no obstante lo cual ha recibido la atención posterior de algunos investigadores, como la profesora Gloria Videla de Rivero9. Además de los títulos decimonónicos o centenarios como Recuerdos de provincia de Domingo Faustino Sarmiento, Mis memorias de Lucio V. Mansilla o Juvenilia de Miguel Cané, la investigadora incorpora al cuerpo de obras (que tal vez ni siquiera constituye serie ni archivo, pero que ella denomina "corpus") Descubrimiento del mundo (1987) de Alicia Jurado, Cuando el tiempo era otro; una historia de infancia en la pampa gringa (1999) de Gladys Onega, y El país de la ilusión (2005) de María Duprat. Más allá de las distancias provinciales que separan los nombres de esas mujeres y las diferencias de edades (en algunos casos veinte años), "todas comparten códigos y valores de época" (188). Lo que le importa subrayar a la investigadora es la fuerza cohesiva del tótem, y cita a Alicia Jurado cuando dice :

He hablado extensamente de mis mayores porque también son parte de mis memorias. No sólo se recombinan sus genes en cada una de mis células y me gobiernan a través de los ocultos mandatos de la herencia; también están los recuerdos transmitidos a mi infancia, en los ejemplos que se me señalaban, en las historias de familia que constituían los orígenes de mi propia, incipiente historia (73).

También en el caso de Alicia Jurado, la infancia es una patria coextensiva de la literatura : “(..) a los cuatro años (...) aprendió a leer. Ella afirma que a través de las páginas de El Nene, su primer libro, entró en el mundo maravilloso de las bibliotecas, otra patria de la que nunca salió" (37).

Dejo de lado la introducción de "El nene" (cuyo sentido se me escapa en este contexto) para manifestar sencillamente mi perplejidad ante la inconsistencia del objeto y la lasitud del corpus. El próximo texto que se glosa es la historia de infancia en la pampa gringa (1999) de Gladys Onega, donde la autora habría consignado:

los zapatillazos de mamá, los cinturonazos de papá (que en realidad iban dirigidos a su hijo preferido), los ronquidos de mamá y los más potentes de papá. Pero, sin embargo, deja entrever, aunque no ponga sobre ella el acento, la mitad llena, los aspectos tiernos de la vida familiar: el regazo gordo de mamá que la acogía compensatoriamente después del castigo, las faldas de papá que la sostenían en cada comida para que la niña anoréxica aceptara el alimento" (195-196).

30 A fuerza de zapatillazos, cinturonazos y potentes e inflamados muslos paternos, la niñaano acepta el don del padre, volviéndose casi un pariente de otro tótem.

31 Arbitrario como puede ser cualquier corpus, Arturo Carrera ha cortado la lista previa para armar una serie diferencial respecto de la cual convendría colocar su propio nombre :

Es grato entre nosotros citar a autores como Gombrowicz, Vallejo, Mastronardi, Lezama, y más cerca en el tiempo a Pizarnik, Silvina Ocampo, Marosa Di Giorgio. (...) también los más jóvenes exploran el viejo tema. Basta citar a Martín Rodríguez, y al mismo Gustavo Romero Borri (Carrera, 1984 : 86).

32 De esa lista yo extraje el nombre de Pizarnik y el de Carrera. No me atrevería a agregar otro si no hubiera una brizna de escritura que me autorizara a ello. Por fortuna, ese nombre y ese trazo existen : es el alumno díscolo de Oscar Masotta, Osvaldo Lamborghini. En una grabación que Arturo Carrera guardaba con el amor del caso, se lo escucha decir :

Yo, Arturo Carrera, escribí una vez, para un diario argentino, una... crítica, un texto sobre Alexandra (sí, hay que llamarla Alexandra, no Alejandra, hay que terminar con esa jota imbécil). Alexandra Pizarnik. Se llamaba "A las niñas mecánicas del templo". Alguien, supuestamente con autoridad, porque sabemos que los diarios 
están llenos de sabios, cambió el título por "El sueño soberano". Yo leí mi propia nota. Y me quedé pensando. A veces pienso. Incluso en Pringles se piensa. Aunque no hay diarios tan grandes como La Opinión, como La Prensa, Razón, la mar en coche. Y pensé que al fin y al cabo, como siempre, le pegaban a la tecla de al lado. Porque se equivocaban. El título era, en verdad, "A las niñas mecánicas del templo". Lo cambiaron a "El sueño soberano". Lo que nunca hubieran podido decir era eso : "El sueño sobre el ano". propósito de Alexandra, del retiro de los sabios, del acontecimiento. Ya está, y no haría falta más que leer en bloque esa pequeña comunidad de obsesionados por la infancia y los niños (o las niñas mecánicas) para cerrar esta intervención, salvo citar los trabajos de Julio Premat sobre Lamborghini (Premat, 2000 y 2008). Pienso, sobre todo, en "El escritor argentino y la transgresión. La orgía de los orígenes en El Fiord de Osvaldo Lamborghini” (Premat, 2000), donde postula El Fiord como una reescritura de Totem y Tabú. Cabezas menos privilegiadas que la de Premat han seguido esa indicación y han creído ver la horda primitiva también en "El niño proletario" (relato que me desagrada tanto que me abstendré de citarlo), pero mejor es no atreverse a tanto : la manía universalizante de Freud ya nos ha dado bastantes dolores de cabeza.

Deberíamos, eso sí, poner a la literatura de infancia de Lamborghini (a sus ficciones teóricas de infancia) del lado del juego, es decir de la profanación, para comprender, por ejemplo, la aclaración de El Pibe Barulo: "Así se destruyó la familia, o digamos «se construyó sobre nuevas bases »" (Lamborghini, 1983 : 266).

A diferencia de lo que sucede en la fábula freudiana, el padre es allí el dueño de la única mujer (y es ésta la que se vuelve contra su hijo). Los demás miembros del clan, Noel (hermano del Pibe) y Barto, lejos de codiciar esa propiedad paterna, se entregan a fundar una civilización totalmente queer (y porque lo queer, sabido es, es la imposibilidad del nombre, el texto postula una danza enloquecida de denominaciones: Pibe Barulo, Gordo Puto, Nal, etc...). Barto, primo del Pibe (adscripto, pues, al mismo Tótem), es quien lo introduce en las delicias de la carne cargada por la popa, que no necesita de ningún principio de exogamia.

No es tanto que Lamborghini retome (con un signo u otro) la teoría de la recapitulación freudiana. Si hace coincidir la ontogenesis con la filogenesis, y la política con el arte, es porque ha encontrado la indicación en esa Alexandra que había subrayado, en un texto de Michaux, la correlación entre soberanía y pérdida de infancia como el paso de lo prehistórico (prebabélico) a lo histórico (posbabélico) : el acontecimiento, la historia : la única forma de seguir escribiendo, es decir : fabricando, al mismo tiempo, experiencia y literatura. Pero para Lamborghini, la historia está fallada desde el comienzo (los sabios, "como siempre, le pegaron a la tecla de al lado") y hay que volver a la infancia para sostener, ahora, "el sueño sobre el ano" como equivalente de la "niña ano (réxica)" de provincias. Porque, en efecto, como se lee en El Pibe Barulo : “Cuál sería la diferencia de la pija en el culo del hombre y en el de la mujer ?" (Lamborghini, 1983 : 250). La respuesta imposible a esa pregunta produce, al mismo tiempo que una nueva antropología (civilizaciones sin tótem ni tabú, un más allá de la transgresión) y una nueva idea de la infancia (la niña mecánica transformada en sueño sin sujeto), un acontecimiento literario. Vuelvo a escuchar a Lamborghini en la grabación pringlense :

El cuerpo tiene un órgano metafórico, el lugar de todas las transmutaciones. Es el lugar poético por excelencia. Es el ano, en el sentido en que es el lugar donde el niño y la niña se encuentran, todavía (subrayando todavía), sin el corte, sin la

Cuadernos LIRICO, 11 | 2014 
diferencia de los sexos. Lugar metafórico, el ano. Mierda, niño, regalo, pene : todo ahí se intercambia. Incluso una gran mujer, mujer de Nietzsche, mujer de Rilke, casi mujer de Freud, Lou Andreas-Salomé, habló de la vagina como eternamente arrendada al ano.

Hasta donde yo sé, la única "casi mujer" en la vida de Freud fue Daniel Paul Schreber, ese extraño juez hipocondríaco que soñó que la historia había terminado y que Dios pretendía engendrar una nueva raza con él, habiéndolo convertido para ello en mujer. Pero ésa, creo, es otra historia de infancia, ya no la infancia queer sino la infancia trans de la humanidad.

\section{BIBLIOGRAFÍA}

Aira, César. Alejandra Pizarnik. Rosario : Beatriz Viterbo, 1998.

Agamben, Giorgio. Infancia e historia. Buenos Aires : Adriana Hidalgo, 2007.

Carrera, Arturo. “Los niños” en Ensayos murmurados. Buenos Aires : Mansalva, 2009 [1984].

Carrera, Arturo. "Muerte de Deleuze" en Ensayos murmurados. Buenos Aires : Mansalva, 2009 [1995]

Castagnino, Raúl. "Evocaciones de infancia y adolescencia en la literatura argentina". Revista Interamericana de Bibliografia, XXXII : 3-4 (338-347), 1982.

Kreidolf, Ernst. Blumen-Märchen. Berna : Alfred Sherz Verlag, 1952.

Lamborghini, Osvaldo. "El Pibe Barulo" en Novelas y cuentos, edición al cuidado de César Aira. Barcelona : del Serbal, 1988 [1983].

Levi-Strauss, Claude. El totemismo en nuestros dias. México : FCE, 1965 [1962].

Lévi-Strauss, Claude. La pensée sauvage. París,1962.

Link, Daniel. "Discurso sobre la infancia”, presentación de Daniel Link a Carrera, Arturo y Prior, Alfredo. Niños que nacieron peinados. Buenos Aires : ArteBA, 21 de mayo de 2007.

Link, Daniel. “Alejandra Pizarnik, el último hombre”, conferencia, Princeton University, 23 de noviembre 2009.

Link, Daniel. "Infancia”, “Niños” y "1955” en Fantasmas. Imaginación y sociedad. Buenos Aires : Eterna Cadencia, 2009b.

Masotta, Oscar. El pop-art. Incluido en Revolución en el arte. Buenos Aires : Edhasa, 2004 [1967].

Molloy, Sylvia. Acto de presencia. La escritura autobiográfica en Hispanoamérica. México : El Colegio de México/ FCE, 1992.

Pieyre de Mandiargues, André. Ruisseau des solitudes suivi de Jacinthes et de Chapeaugaga. París : Gallimard, 1968.

Pizarnik, Alejandra. Correspondencia Pizarnik, edición a cargo de Ivonne Bordelois. Buenos Aires : Seix Barral, 1998. 
Pizarnik, Alejandra. Poesía completa, edición a cargo de Ana Becciu. Barcelona : Lumen, 2001.

Pizarnik, Alejandra Diarios. Barcelona : Lumen, Barcelona, 2003.

Pizarnik, Alejandra. Prosa completa. Buenos Aires : Lumen, 2003b.

Premat, Julio. "El escritor argentino y la transgresión. La orgía de los orígenes en El Fiord de Osvaldo Lamborghini”, Ponencia leída en el séptimo coloquio internacional de CRICCAL, "Fiesta y celebraciones" (París, mayo 2000).

Premat, Julio. Héroes sin atributos. Buenos Aires : Fondo de Cultura Económica, 2009.

Schérer, René y Hocquenguem, Guy. Co-ire. Album sistemático de la infancia. Barcelona : Anagrama, 1979 [1976].

Videla de Rivero, Gloria. "Recuerdos de infancia y adolescencia en la literatura argentina". Universidad de Cuyo : Revista de Literaturas Modernas, 2006 (185-206).

\section{NOTAS}

1. Se descompone en o inicial, prefijo de la tercera persona; $t$ epentética (para evitar la coalescencia de las vocales), $m$ (posesivo) an (sufijo de tercera persona), ote, que expresa el parentesco entre Ego y un hermano, hombre y mujer, y define, por lo tanto, el grupo exógamo en el nivel de generación del sujeto. Cf. Levi-Strauss, 1962, p. 33.

2. Comunicación personal.

3. “Ojalá viva mucho ; es mi único punto de referencia” (Pizarnik, 1998 : 289)

4. Lettres françaises, 6, Buenos Aires, 1o de noviembre de 1942 . La revista tiene el mismo formato que Sur : "cahiers trimestriels de littérature française, édités par les soins de la revue Sur avec la collaboration des écrivains français résidents en France et à l'Etranger". Los subrayados reproducen los subrayados de la autora.

5. “ ¿Y el sabor y el aroma de la infancia que Proust rescata de una manera que nos parece perfecta?".

6. “Según Lang, importa poco de qué modo llegaron los clanes a darse nombres de animales. Basta con admitir que hubo un día en el que advirtieron que llevaban tales nombres, sin que supieran determinar la causa. El origen de los mismos había sido olvidado. Entonces habrían intentado obtener una explicación especulativa de su denominación, y dada la importancia que atribuían a los nombres, tenían que llegar necesariamente a todas las ideas contenidas en el sistema totémico. Los nombres no eran para los primitivos, como tampoco lo son para los salvajes de nuestros días, e incluso para nuestros niños, algo convencional e indiferente, sino atributos significativos y esenciales. El nombre de un individuo es una de las partes esenciales de su persona y quizá incluso de su alma. El hecho de llevar el mismo nombre que un animal dado debió de inclinar al primitivo a admitir un importante y misterioso enlace entre su persona y la especie animal cuyo nombre llevaba. ¿Y qué otro enlace hubiera podido concebir sino la consanguinidad? Pero admitido éste, fundándolo en la identidad de nombre, todas las prescripciones totémicas, incluso la exogamia, habían de derivarse de él como consecuencia directa del tabú de consanguinidad".

7. "Como una de las últimas opiniones formuladas sobre esta cuestión citaré la que Wundt expresa en sus Elementos de la psicología de los pueblos (1912) : "Teniendo en cuenta todos estos hechos, podemos admitir, sin temor a apartarnos demasiado de la verdad, que la cultura totémica ha constituido en todas partes una fase preliminar del desarrollo ulterior y un estado de transmisión entre la humanidad primitiva y la época de los héroes y de los dioses »" (139). 
8. "Nos limitaremos a hacer resaltar dos interesantes coincidencias de nuestro caso con el totemismo; la completa identificación con el animal totémico y la actitud ambivalente con respecto a él. Basándonos en estas observaciones nos creemos autorizados para sustituir en la fórmula del totemismo - por lo que al hombre se refiere- el animal totémico por el padre. Pero, una vez efectuada tal sustitución, nos damos cuenta de que no hemos realizado nada nuevo ni dado, en verdad, un paso muy atrevido, pues los mismos primitivos proclaman esta relación, y en todos aquellos pueblos en los que hallamos aún vigente el sistema totémico es considerado el tótem como un antepasado. Todo lo que hemos hecho no es sino tomar en su sentido literal una manifestación de estos pueblos que ha desconcertado siempre a los etnólogos, los cuales la han eludido, relegándola a un último término. El psicoanálisis nos invita, por el contrario, a recogerla y enlazar a ella una tentativa de explicación del totemismo".

9. Videla de Rivero, 2006. En adelante, se indican las páginas entre paréntesis.

\section{RESÚMENES}

A menudo se confunde la infancia (un estado de la imaginación) con los niños y las niñas, que son quienes vivirían con mayor libertad en ese estado.

Pero evocar la infancia es antes evocar una lógica (la lógica de la ausencia, de lo que va a desaparecer, de lo que falta en su lugar, la lógica de la fuga y el rapto, en fin : la lógica de lo imaginario) antes que una edad más o menos dorada.

Para evaluar esa distancia entre lo existente y lo posible se examinaran, fatalmente, algunos fragmentos de texto (ninguna consideración estratégica: los más a mano): de Pizarnik, de Carrera, de Osvaldo Lamborghini.

La literatura y la infancia como campos correlativos de experimentación (es decir, como experiencias cuya salida se desconoce).

On confond souvent l'enfance (un état de l'imagination) et les enfants qui vivraient cet état dans la plus grande liberté. Mais évoquer l'enfance, c'est avant tout évoquer une logique (la logique de l'absence, de ce qui va disparaître, de ce qui manque, la logique de la fugue et du rapt : la logique de l'imaginaire) plutôt qu'une sorte d'âge d'or. Afin d'évaluer cette distance entre l'existant et le possible on examinera quelques fragments de textes d'Alejandra Pizarnik, Arturo Carrera et Osvaldo Lamborghini. La littérature et l'enfance comme champs corrélatifs d'expérimentation (autrement dit comme expérience dont on ignore l'issue).

Childhood (a state of imagination) is often mistaken with childreen who would live with more freedom in that state. But to recall childhood means to recall a logic (logic of absence, of what is disappearing, what is missing, a logic of escape and abduction) instead of a golden age.

To assess the distance between the existant and the possiblem we fataly will examine some text's fragments (no strategic consideration whatsoever : just what was in hand) : Pizarnik, Carrera, Osvaldo Lamborghini.

Literature and childhood will be studied as correlative fields of experimentation (as experiences with an unknown way-out). 
ÍNDICE

Mots-clés: imaginaire, logique de l'absence, Alejandra Pizarnik, Arturo Carrera, Osvaldo Lamborghini

Palabras claves: imaginario, lógica de ausencia

Keywords: imaginary, logic of absence

\section{AUTOR}

DANIEL LINK

UBA/ UNTREF 